\title{
Increasing Social Behaviour through Self-Management Strategy at the Children with Autism in the Inclusive Kindergarten
}

\author{
Marlina \\ Department of Special Education, Faculty of Education, Universitas Negeri Padang \\ Email: marlina.muluk@gmail.com
}

\begin{abstract}
This study aims to increase these social behaviors children with autism through selfmanagement strategy (SMS by peers. The participants of this study were three children with autism and three normal students in the Kindergarten School. The effectiveness of the intervention was measured in the learning process, recess, and physical exercise activities. The data were collected through video recordings for 10 minutes. In addition, this study has validated the data for both internal and external validity by using the Social Response Scale to the class teachers and special teachers. The results show that the SMS that was mediated by peers has an impact on the social behaviors, including in starting the conversation, starting the game, and keeping the interaction of the children with autism. Finally, some limitations and further research are discussed.
\end{abstract}

Keywords: social behavior, self-management strategy, children with autism.

\section{Introduction}

One of the characteristics in children with autism is the pervasive disorders in social behaviour. That disorder can be reduced by teaching them how to behave in a socially appropriate way. When the children with autism acquire limited social response, they have problems of social skill according to their age. The delays of social behaviour in children with autism will disturb the process of their social integration. Therefore, a systematic teaching of social skills is important for children with autism. For normal children, social behaviour can be carried out in their everyday life, but for the children with autism, social behaviour does not happen by itself. On the contrary, children with autism need support for systematic learning both by teachers and peers.

Over the past 10 years, the Indonesian government had sought to put the children with autism in the regular school. This is reinforced by the enactment of Regulation from National Education Minister No, 70 the Year 2009 on inclusive education for learners who have abnormalities and experienced intelligence potential and/ or special talents. However, there is still little evidence that shows the increase of social interaction on children with autism with the normal peers. Several types of research has shown that children with autism have the lack of the prerequisite skills in social skills, those skills can be taught with explicit teaching support (M.S. Bhatia, 2010; Wong, et al, 2015; Singh, et al, 2011). If the teachers 
do not provide training and skill in facilitating social interaction for children, the children with autism will continue to have problems in their social behaviour. Therefore, a systematic approach is needed to facilitate the improvement of social skills on children with autism in inclusive education settings.

The approach mentioned above is the approach that uses the natural environmental setting in natural context to change children behaviour. The failure in maintaining the behaviour is mostly due to the context that is highly controlled and dominated by adults (such as teachers, parents, and other professionals). Mathews, et.al (2017) performed the research to increase the social skills of children with autism by using social skills training programs. The result of research showed that there is an increase in the verbal interaction of children with autism. Zhang \& Wheeler (2011) suggest that learning social skills by using peer involvement has the positive effect on children with autism. The influence is among others in terms of commenting, questioning, social interaction, and so on. This finding suggests that teaching by involving peers on children with autism is very effective to be implemented in the inclusive setting. Mathews, et.al (2013) investigated the influence of social skills interaction in increasing the social skills of children with autism and children with disruptive behavior disorders. These research findings indicate that peer involvement is very effective in increasing social skills of children with autism.

One of the important components in teaching social skills to children with autism is the reinforcement. However, that reinforcement usually comes from adults. Therefore, the reinforcement from an adult is transferred to the reinforcement of the children themselves, which is also called as self-management. The self-management strategy (SMS) transfers the responsibility from the teachers to the individual child (Singh, et al, 2011). The SMS teaches the children to (1) differentiate between appropriate and inappropriate behaviours, (2) evaluate self-behaviour, (3) monitor the behaviour of themselves from time to time, and (4) provide reinforcement when the appropriate behaviour has been performed. Southall \& Gast (2011) conducted the research of SMS to teach children with autism how to play appropriately in the natural environment. There is an increase of opportunity to interact with the peers without the involvement of adults. This SMS has made the children become active in the process of intervention and classroom environment (Hansen, et al, 2013). Bruce \& Hansson (2011) investigated the combination of functional analysis procedures and SMS on two Senior High School students with mental disabilities in regular schools to solve the behavioural problems and increase appropriate social behaviour. The results indicated that 
both students showed the decrease of inappropriate social response and the increase of alternative functional response.

In Indonesia, social skills intervention in children with autism has never used a SMS. A frequently used intervention is to use an adult as a mediator. Based on the above problems, this research has purposed: (1) determine the effectiveness of SMS in increasing social behaviour of children with autism; (2) determine the changes in social behaviour of children with autism after the application of SMS.

\section{Materials and Method}

\section{Subject of Research}

The subject of research involves three children with autism in the Kindergarten School at the TK Permata Hati, Padang City. These three children study in Kindergarten School that provides inclusive education in Padang, West Sumatera, Indonesia. The cognitive abilities of these three subjects were on average, they have language skills and social behaviour that are almost similar, and their adaptive skills were below standard. Peer mediator is selected by the teacher by using the Instrument Identification Peer Mediator (IIPM) and the teacher nominations. The teachers choose peer mediator (PM) that has good social skills (such as offering assistance to others, asking others to join in an activity, and taking turns in conversation).

\section{Setting and Equipment}

Six PM that had been selected were given training for 1 week ( 3 meetings). Every two chosen PM were paired with an autistic child. The six selected PM were provided with the training performed in the separate classes. The training material for PM was made in the form of the video that was packaged in Compact Disk. The content of video included a brief description about SMS, the steps in implementing SMS, how to provide reinforcement for children with autism if they behaved appropriately, and the practical application of SMS. The reinforcement for PM was made in form of sticker cards that were accumulated in the weekend.

\section{Measurement of Self-Management Strategy}

Self-management behaviour of children with autism was measured for 15 minutes during breaks by using a self-recording sheet, which was the recording of children social behaviour every 1 minute. If the child showed appropriate social behaviour, PM would give a score of 1 and if the children social behaviour is not appropriate, PM gave a score of 0 on 
the behaviour record sheet. Every child with autism had three social behaviours, where they were responsible for monitoring their own behaviour. The children with autism were taught to monitor and record themselves according to three target behaviours, namely: (1) starting the conversation (I start talking with friends), (2) starting the game (I start playing with my friends), and (3) keeping interaction (I keep playing and talking with my friends).

Starting the conversation is the verbal expressions spoken directly by children with autism. If an autistic child says "I want to play with Firman", then it will be scored as behaviour in starting the conversation. Starting the game is every verbal and nonverbal initiation in playing activities. If the children hold the hand of PM or say "let's play," it will be scored as starting the game. Maintaining the interaction is the direct involvement of children with autism either verbally or nonverbally during play with peers (such as requesting, answering questions, asking for help) will be scored as maintaining the interaction.

Children with autism and PM were recorded for 10 minutes in playing activities before, during, and after SMS. The playing activities were recorded every day, which includes three social behaviours. Intervention social validity is measured by special education teachers and classroom teachers by filling the Social Responsiveness Scale (SRS) that refers to Singh et.al (2011). SRS data was collected at the baseline, intervention, and after an intervention. SRS is the grading scale that uses a quantitative approach to measure social behavioural symptoms that appear in the natural setting.

\section{Inter-observer Agreement}

Before collecting the research data, the trained observers perform structured social skills teaching in children with autism and this is recorded for 30 minutes. Social skills behaviour is measured by two observers. The agreement for scoring is when both observers identify the behaviour with the same code of conduct. While disagreement is measured in the opposite way. The inter-observer agreement is measured by dividing the number of agreements with the total number of agreements and then the result is added with the disagreements and then multiplied by 100 . During the observation, at least $25 \%$ of each autistic children were scored by two observers.

\section{Experiment Design}


This research uses multiple baselines across subjects. At the phase of baseline, the children with autism are not given any intervention. In the phase of the intervention, the children with autism are given intervention with SMS.

\section{Self-Management Training}

Each PM is given description protocol of SMS and social behaviour observation sheet. Observation sheet is used to record social behaviour. SMS is taught in the following manner: (1) the experimenter explains the use of SMS to PM; (2) PM identifies the appropriate social behaviour; (3) modeling the SMS by the experimenter; (4) The sixth PM imitate the SMS and are given feedback; (5) each of PM and experimenter take the data together in order to determine the effectiveness of intervention and feedback that is given to children with autism.

\section{Result}

The result of research is focused on three target behaviours, which are starting the conversation, starting the game, and maintaining the interaction. During the phase of baseline, the behaviour of autistic children $\mathrm{AH}, \mathrm{BN}$, and $\mathrm{CH}$ in starting the conversation, starting the game, and maintaining the interactions are in a low category. The three children with autism consistently show a low social behaviour. During the intervention phase with SMS, each of the children with autism shows different social behaviour. There is an improvement in the social behaviour of children with autism, compared with the baseline phase. However, when the SMS is applicated, the social behaviour of children with autism has increased drastically. The percentage score on the social behaviour is presented in table 1.

Table 1. Improvement of Children's with Autism Social Behaviour on $\mathrm{AH}, \mathrm{BN}$, and $\mathrm{CH}$ at Baseline Phase and at SMS Phase

\begin{tabular}{|c|l|l|r|r|}
\hline No & Subject & \multicolumn{1}{|c|}{ Social Behaviour } & Baseline Mean & \multicolumn{1}{c|}{ SMS Mean } \\
\hline \multirow{2}{*}{1} & \multirow{2}{*}{ AH } & Maintaining the interaction & $34,60 \%$ & $42,20 \%$ \\
\cline { 3 - 5 } & & Starting the conversation & $22,00 \%$ & $25,60 \%$ \\
\cline { 3 - 5 } & & Starting the game & $8,40 \%$ & $16,60 \%$ \\
\hline 2 & \multirow{2}{*}{ BN } & Maintaining the interaction & $12,50 \%$ & $30,80 \%$ \\
\cline { 3 - 5 } & & Starting the conversation & $15,67 \%$ & $31,20 \%$ \\
\cline { 3 - 5 } & & Starting the game & $11,17 \%$ & $14,20 \%$ \\
\hline 3 & \multirow{2}{*}{$\mathrm{CH}$} & Maintaining the interaction & $11,86 \%$ & $23,80 \%$ \\
\cline { 3 - 5 } & & Starting the conversation & $11,00 \%$ & $17,40 \%$ \\
\cline { 3 - 5 } & & Starting the game & $11,29 \%$ & $33,20 \%$ \\
\hline
\end{tabular}


The social behaviour of children with autism is also observed by regular teachers and special education teachers by using the SRS. Table 2 shows the condition before, during, and after the intervention. On the subject of $\mathrm{AH}$, the comparison of before and after the assessment by special education teachers indicates that all social behaviours increase and it is maintained at the follow-up session. While the regular teachers' assessment is that the social communication and behaviour of autism of AH decreases during the follow-up session.

Table 2. Assessment of Special Teachers and Regular Teachers on Social Behaviour on Social Responsibility Scales

\begin{tabular}{|c|c|c|c|c|c|c|c|c|c|c|}
\hline & \multicolumn{2}{|c|}{$\begin{array}{c}\text { Social } \\
\text { Awareness }\end{array}$} & \multicolumn{2}{|c|}{$\begin{array}{c}\text { Social } \\
\text { Cognition }\end{array}$} & \multicolumn{2}{|c|}{$\begin{array}{c}\text { Social } \\
\text { Communication }\end{array}$} & \multicolumn{2}{|c|}{$\begin{array}{c}\text { Social } \\
\text { Motivation }\end{array}$} & \multicolumn{2}{|c|}{$\begin{array}{c}\text { Autistics } \\
\text { Mannerisms }\end{array}$} \\
\hline & ST & RCT & ST & RCT & ST & RCT & ST & $\mathrm{RCT}$ & ST & RCT \\
\hline \multicolumn{11}{|l|}{ Subject AH } \\
\hline Before & 69 & 68 & 70 & 70 & 66 & 67 & 69 & 70 & 68 & 68 \\
\hline During & 74 & 73 & 73 & 76 & 70 & 70 & 74 & 75 & 75 & 71 \\
\hline Follow Up & 72 & 72 & 70 & 72 & 70 & 68 & 71 & 74 & 73 & 69 \\
\hline \multicolumn{11}{|l|}{ Subject BN } \\
\hline Before & 73 & 72 & 75 & 75 & 76 & 75 & 77 & 78 & 76 & 75 \\
\hline During & 78 & 79 & 80 & 81 & 79 & 80 & 71 & 72 & 83 & 79 \\
\hline Follow Up & 76 & 75 & 77 & 77 & 75 & 78 & 70 & 70 & 82 & 78 \\
\hline \multicolumn{11}{|l|}{ Subject CH } \\
\hline Before & 70 & 70 & 73 & 74 & 77 & 75 & 74 & 76 & 70 & 70 \\
\hline During & 74 & 77 & 78 & 75 & 82 & 81 & 80 & 80 & 76 & 75 \\
\hline Follow Up & 74 & 76 & 77 & 72 & 80 & 80 & 79 & 80 & 75 & 75 \\
\hline
\end{tabular}

ST $=$ Special Teachers $\quad \mathrm{CT}=$ Regular Classroom Teachers

On the subject of $\mathrm{BN}$, special education teachers and regular teachers have a similar score about social cognition and social motivation. While the autistic behaviour of $\mathrm{BN}$ between special education teachers and regular teachers have different scorings. Finally, on the subject of $\mathrm{CH}$, special education teachers and regular teachers have similar scorings on autistic behaviour and social communication of $\mathrm{CH}$ subjects. While on the social awareness and social cognition, the scoring of special education teachers and regular teachers is fluctuating.

\section{Discussion}

The results show that the SMS is effective in teaching social behaviour on maintaining the interaction. In this study, when the children with autism interact with peers that have been trained, social interaction comes naturally and according to age, with attention and 
communication that are appropriate to the context of the interaction. There is an obvious difference in the initial condition, where the social interaction appears disconnected (for example, a glimpse of eye contact) and communicative exchanges that are very minimal. That interaction allows more opportunity for trained peers to maintain and sustain the attention of children with autism.

These research findings also show that the natural school practices can help and increase the generalization of social behaviour in several settings (such as at breaks and sports activities). The most consistent finding is that the social behaviour of paying attention from the three children with autism increases during sports hour. This is because the activities performed by children with autism are more structured with the guidance from the teacher through group tasks, while the activities during the breaks and lunch are performed independently (Beaulieu, et. al, 2014).

In accordance with the learning process in the inclusive school, the research findings provide the effect on children with autism and peer mediators. The research findings show that there is an improvement in the attitudes and perceptions of peer mediators toward children with autism. Peer mediators are more accepting, having a positive perspective, honing the leadership skills, having more confidence and self-esteem, and feeling proud to help their friend. The implementation of peer involvement on learning in the inclusive school also affect to the children academic and social progress of normal children, among others: (1) increasing the conversational skills (Beaulieu, et. al, 2014); (2) learning to accept and appreciate individual differences among peers; (3) increasing the confidence by becoming the model of positive behaviour (Gena, 2006); (4) building the character by giving the boost to the children with special needs when participating in learning activities in the classroom; and (5) developing leadership skills and helping teachers to increase the social skills of children with special needs (Bhatia et.al, 2010).

From the aspect of educational psychology on children with autism and children with special needs, it generally shows that children will learn with fun if mediated by their peers. This is because learning that is mediated by peers can provide the flexibility to think, act, and behave due to the absence of psychological burden with a friend. These research findings are related to the concept of joyful learning. The atmosphere of fun learning can focus the attention of children on learning so that the time on task is high. According to the result of research, the higher time on task is proven to increase the learning outcomes. Fun learning is characterized by: (1) the students are involved in various activities that develop 
the understanding and ability with the emphasis on learning by doing; (2) the teachers use variety of equipment and different ways of motivating the spirit, including the use of environment as the source of learning to make interesting, fun, and suitable learning for children; (3) the teachers manage their classrooms by displaying books and learning materials that are more attractive and providing the 'reading corner'; (4) the teachers apply the way of teaching that is more cooperative and interactive, including study groups; (5) the teachers encourage the children to find their own ways of solving the problem, expressing their ideas, and involving children in creating their school environment.

As in the applied research, this study also has limitations. First, the available material is too varied. Although this study allows the children with autism to make choices with whom they want to play and for what they want to play because it has impacts on the data relating to specific materials that have more motivation attributes. To that end, the next research will be done by using several activities that have the similar quality. For example, the interaction activity or the activity of changing toy only. By limiting these activities, the reinforcement quality has the similar quality, so that the obtained data is also relatively similar. Another limitation is the generalization of these research findings to the large population due to the limited sample size of only three children with autism. The application of this strategy to the larger number of children with autism and for the children population that is more diverse (such as the children with concentration problems and hyperactivity, children with social anxiety disorder, and so on) allows for the generalization that is wider than the used techniques.

\section{Conclusion}

Based on the results of research and discussion it can be concluded that SMS is effective to improve social behavior in children with autism. Therefore, teachers need to implement SMS in an integrated learning activities.

\section{References}

Beaulieu, L., Hanley, G.P. and Santiago, J.L., 2014. Improving the conversational skills of a college student with peer-mediated behavioral skills training. The Analysis of verbal behavior, 30(1), pp.48-53.

Bhatia, M. S., Rajender, G., Malhotra, S., Kanwal, K., \& Chaudhary, D. (2010). Management of social skill deficits in autism spectrum disorders. Delhi Psychiatry Journal, Review Article, 13, pp.262-274. 
Bruce, B., \& Hansson, K. 2011. Promoting peer interaction. In Autism Spectrum DisordersFrom Genes to Environment. InTech.

Gena, A. 2006. The effects of prompting and social reinforcement on establishing social interactions with peers during the inclusion of four children with autism in preschool. International Journal of Psychology, 41, pp.541-554.

Hansen, B. D., Wills, H. P., Kamps, D. M., \& Greenwood, C. R. 2014. The effects of function-based self-management interventions on student behaviour. Journal of Emotional and Behavioural Disorders, 22, pp.149-159.

Harper, C. B., Symon, J. B., \& Frea, W. D. 2008. Recess is time-in: Using peers to improve social skills of children with autism. Journal of Autism and Developmental Disorders, 38 , pp.815-826.

Mathews, T. L., Vatland, C., Lugo, A. M., Koenig, E. A., \& Gilroy, S. P. 2017. Training Peer Models to Promote Social Skills: Considerations for Practice. Focus on Autism and Other Developmental Disabilities, 1(1), pp.1-11. 1088357617735814.

Mathews, T. L., Erkfritz-Gay, K. N., Knight, J., Lancaster, B. M., \& Kupzyk, K. A. 2013. The effects of social skills training on children with autism spectrum disorders and disruptive behavior disorders. Children's Health Care, 42(4), pp.311-332.

Morrison, L., Kamps, D., Garcia, J., \& Parker, D. 2001. Peer mediation and monitoring strategies to improve initiations and social skills for students with autism. Journal of Positive Behaviour Interventions, 3 (4), pp.237-250.

Singh, N. N., Lancioni, G. E., Manikam, R., Winton, A. S., Singh, A. N., Singh, J., \& Singh, A. D. 2011. A mindfulness-based strategy for self-management of aggressive behavior in adolescents with autism. Research in Autism Spectrum Disorders, 5(3), pp.1153-1158.

Singh, N. N., Lancioni, G. E., Manikam, R., Winton, A. S., Singh, A. N., Singh, J., \& Singh, A. D. 2011. A mindfulness-based strategy for self-management of aggressive behavior in adolescents with autism. Research in Autism Spectrum Disorders, 5(3), pp.1153-1158.

Wong, C., Odom, S.L., Hume, K.A., Cox, A.W., Fettig, A., Kucharczyk, S., Brock, M.E., Plavnick, J.B., Fleury, V.P. and Schultz, T.R., 2015. Evidence-based practices for children, youth, and young adults with autism spectrum disorder: A comprehensive review. Journal of Autism and Developmental Disorders, 45(7), pp.1951-1966.

Sandall, S., Hemmeter, M. L., McLean, M. D., \& Smith, B. J. 2005. Increasing the social interactions of preschool children with disabilities during mealtime: The effects of an interactive placemat game. Education and Treatment of Children, 22 (1): pp.1-19.

Scattone, D. 2007. Social skills interventions for children with autism. Psychology in the Schools, 44 (7), pp.717-726. 
Shukla-Mehta, S., Miller, T., \& Callahan, K. J. 2010. Evaluating the effectiveness of video instruction on social and communication skills training for children with autism spectrum disorders: A review of the literature. Focus on Autism and Other Developmental Disabilities, 25 (1), pp.23-36.

Singh, N. N., Lancioni, G. E., Manikam, R., Winton, A. S., Singh, A. N., Singh, J., \& Singh, A. D. 2011. A mindfulness-based strategy for self-management of aggressive behaviour in adolescents with autism. Research in Autism Spectrum Disorders, 5 (3), pp.1153-1158.

Southall, C. M., \& Gast, D. L. 2011. Self-management procedures: A comparison across the autism spectrum. Education and Training in Autism and Developmental Disabilities, pp.155-171.

Wilkinson, L. A. 2008. Self-management for children with high-functioning autism spectrum disorders. Intervention in School and Clinic, 43 (3), pp.150-157.

Zhang, J., \& Wheeler, J. J. 2011. A meta-analysis of peer-mediated interventions for young children with autism spectrum disorders. Education and Training in Autism and Developmental Disabilities, pp.62-77. 